This article was downloaded by: [York University Libraries]

On: 04 March 2015, At: 17:25

Publisher: Taylor \& Francis

Informa Ltd Registered in England and Wales Registered Number: 1072954 Registered office: Mortimer House, 37-41 Mortimer Street, London W1T 3J H, UK

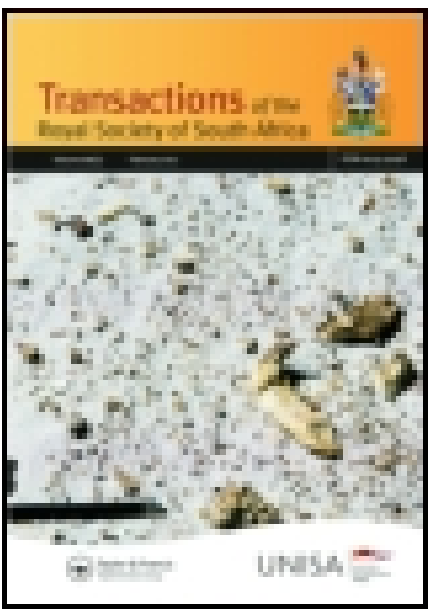

\title{
Transactions of the South African Philosophical Society
}

Publication details, including instructions for authors and subscription information:

http:/ / www. tandfonline.com/loi/ttrs19

\section{ON THE STRUCTURE AND AFFINITIES OF THE ENDOTHIODONT REPTILES}

\author{
R. Broom M.D., B.Sc., C.M.Z.S. ${ }^{\text {a }}$ \\ ${ }^{a}$ Victoria College, Stellenbosch \\ Published online: 28 J un 2010.
}

To cite this article: R. Broom M.D., B.Sc., C.M.Z.S. (1904) ON THE STRUCTURE AND AFFINITIES OF THE ENDOTHIODONT REPTILES, Transactions of the South African Philosophical Society, 15:1, 259-282, DOI: $10.1080 / 21560382.1904 .9626441$

To link to this article: http:// dx. doi.org/ 10.1080/21560382.1904.9626441

\section{PLEASE SCROLL DOWN FOR ARTICLE}

Taylor \& Francis makes every effort to ensure the accuracy of all the information (the "Content") contained in the publications on our platform. However, Taylor \& Francis, our agents, and our licensors make no representations or warranties whatsoever as to the accuracy, completeness, or suitability for any purpose of the Content. Any opinions and views expressed in this publication are the opinions and views of the authors, and are not the views of or endorsed by Taylor \& Francis. The accuracy of the Content should not be relied upon and should be independently verified with primary sources of information. Taylor and Francis shall not be liable for any losses, actions, claims, proceedings, demands, costs, expenses, damages, and other liabilities whatsoever or howsoever caused arising directly or indirectly in connection with, in relation to or arising out of the use of the Content.

This article may be used for research, teaching, and private study purposes. Any substantial or systematic reproduction, redistribution, reselling, loan, sub-licensing, systematic supply, or distribution in any form to anyone is expressly forbidden. Terms \& Conditions of access and use can be found at http://www.tandfonline.com/page/termsand-conditions 


\section{ON THE STRUCTURE AND AFFINITIES OF THF. ENDOTHIODONT REPTILES.}

By R. Broom, M.D., B.Sc., C.M.Z.S., Victoria College, Stellenbosch.

(Read September 28, 1904.)

(Plates XII., XIII., XIV.)

In 1868 Huxley (1) described, under the name Pristerodon McKayi, an imperfect skull that had been found by Mr. G. McKay at East London. He regarded it as a "lacertilian skull," and no one seems to have doubted the interpretation till Seeley (2) examined the specimen in 1894, and expressed the opinion that the skull is that of an Endothiodont. There is now little doubt that Seeley's view is correct.

In 1876 Owen (3) deseribed and figured in his Catalogue of South African Fossil Reptiles "a cast of the fore part of the skull and corresponding part of the mandible" of a large Anomodont reptile, which he named Endothiodon bathystoma. The original is stated to have been found in the Sneewberg Range, and to be in the "Museum of Albany, Cape of Good Hope." In Lydekker's (4) British Museum Catalogue, 1890, the type is stated to have been presented to the British Museum by the "Directors of the Museum at Albany, Cape Colony." There is still in the Albany Museum, Grahamstown, some bones, which are said to have belonged to the same individual as the type snout. The principal of these are the occiput and a few cervical vertebræ.

Owen was struck by the close resemblance of the snout to that of Oudenodon, especially in the absence of teeth from the alveolar borders of both upper and lower jaws. The new form was, however, observed to differ from Oudenodon in having a number of rounded teeth on what was regarded as the " palatal surface of the maxillary 
and palatine bones." Similar rounded teeth were found on the mandible. Owen, in this first description of Endothiodon, does not give a very clear idea of the anatomy of the new type.

In 1879, Owen (5) published an important paper on the Endothiodont Reptilia, in which he gives further evidence of the structure of Endothiodon bathystoma, and describes a well-preserved snout of a new Endothiodont which he names Endothiodon miscries. $\mathrm{He}$ discusses at some length the affinities of the group, and concludes that the Endothiodonts are allied to Oudenodon, but belong to a distinct family of the order Anomodontia. The teeth of the upper jaw he regards as belonging to the palatine bones.

In 1890 Lydekker (4) re-examined the British Museum Endothiodont specimens, and placed them in the family Endothiodontidæ of the sub-order Dicynodontia. Lydekker recognised that the upper jaw teeth belong to the maxillary bone, and thus showed that Endothiodon is even more closely allied to Oudenodon than had been believed by Owen. An imperfect skull which Owen had described under the name Theriognathus microps is believed by Lydekker to be that of a young Endothiodon uniseries. I am not aware that this opinion has been confirmed by any more recent worker, and though any opinion of this nature expressed by Lydekker must carry great weight, I am inclined to think that Lydekker is mistaken.

In 1892 Seeley (6) described and figured the lower jaw of Endothiodon bathystoma, and showed the structure of the teeth. He concludes that "all the characters of the dentition suggest near affinity with the Theriodontia."

In 1895 Seeley (2) further discussed the affinities of the Endothiodonts. He pointed out for the first time that Pristerodon, of Huxley, is really an Endothiodont. $\mathrm{He}$ also expressed the opinion that Endothiodon uniseries of Owen should be made the type of a new genus which he named Esoterodon. Owen in 1879 had suggested the possibility of E. uniseries belonging to a different genus from Endothiodon bathystoma, and though Lydekker agrees with Owen in making the one genus include both species, I am of opinion that Seeley's view is the more correct. Seeley described a new genus Cryptocynodon allied to Esoterodon. This is founded on a small imperfect skull which is too imperfectly preserved to reveal much that is new in the structure of the Endothiodont skull. Seeley differs from Owen and Lydekker in failing to recognise any marked Dicynodont characters in the Endothiodont skull, which he considers is much more nearly related to the Theriodont type. $\mathrm{He}$ regards the Endothiodonts as forming a distinct sub-order Endothio- 
dontia, of the order Therosuchia, one of the two principal orders into which he divides the Anomodontia.

Within the last few years the only papers dealing with the Endothiodonts have been one or two by myself $(7,8,9,10,11)$, dealing with certain points in the anatomy, and describing a few new forms. As, however, a considerable number of new specimens have been discovered, it is now possible to give a pretty complete account of the structure of the skeleton of the Endothiodonts.

\section{Endothiodon bathystoma, Owen.}

About a year ago Mr. J. M. Bain presented to the South African Museum a number of fossil bones collected by his father, Mr. T. Bain, many of which are of great interest. Perhaps the most important specimen is the greater part of a skeleton of Endothodon bathystoma. There are preserved the antorbital portion of the skull, the front half of the lower jaw, the parietal crest, the greater part of the occiput, and two fragments of the arches. Of the vertebræ there are preserved 19 of the presacral series and 4 sacral vertebre. It is possible that all the vertebræ from the first to the seventeenth inclusive are preserved, but there are three points in the series where there may be a break. Immediately behind the axis, one, or possibly two, vertebræ may be missing. On the other hand it is quite possible all the cervical vertebræ are present. Breaks occur between the fifth and sixth, and between the fifteenth and sixteenth vertebre, but it is improbable that any vertebræ are missing at these points. Behind the seventeenth vertebra there are evidently a number of vertebræ missing, only two being preserved out of possibly seven. The two may be the twenty-second and the twenty-sixth. The sacrum is composed of four vertebræ, all of which are present and fairly well preserved. Of the shoulder girdle there are only preserved the upper and the lower part of the right scapula, and a fragment of the right precoracoid. The proximal half of the right humerus is preserved. The pelvis is fairly well preserved, both ilia being practically complete, and the upper parts of both pubes and ischia being present. The proximal and distal ends of both femora are preserved with the proximal ends of the tibia and fibula of both sides.

In addition to this very fine specimen there is in the South African Museum the anterior part of the mandible of another individual.

The chief now features that are revealed in the structure of the skull are the great width of the occiput, and the presence of a 
large parietal crest. Though the skull is very considerably crushed, it is less crushed than is the type specimen. Only a few of the cranial sutures can be distinctly made out.

The premaxillary bones are almost certainly united as in Dicynodon, and are comparatively narrow. They appear to extend backwards between the nasals on the upper surface of the skull, as Owen believed to be the case in Esoterodon unisevies, and as is the case in many other Anomodonts. The tooth-like processes in the front of the beak appear to be formed entirely by the premaxillaries. They are much more feebly developed than the caniniform processes in the larger species of Oudenodon. In front of the processes the edges of the premaxillaries pass upwards and inwards, meeting each other like the letter $\mathbf{V}$, and forming a narrower depression which. looks forwards and downwards, and which no doubt accommodated. the sharp hooked point of the mandible. There is no evidence of any teeth in connection with the premaxillaries.

The maxillary bone is of large size, and forms the greater part of the side of the face. Extending back from the tooth-like process of the premaxillary the maxillary forms a narrow ridge which was probably in life covered with horn. Immediately within the ridge is a rather broad groove to accommodate the horny edge of the mandible. This groove is practically devoid of teeth, but on one side there is seen to be a single tooth about $4 \mathrm{~cm}$. behind the toothlike process. The specimen is not sufficiently developed to show fully the arrangement of the teeth, and owing to the nature of the matrix further development does not seem advisable. There is, however, evident a row of 9 or 10 large teeth on the inner side of the groove. As the row passes backwards other teeth appear by the side of the main row, and at the back part of the row there are 3 or 4 teeth side by side. At the front of the toothed region in the middle line are two fairly large teeth. Unfortunately it is impossible with. out sectioning the specimen to decide in which bone these median teeth are implanted. Possibly they are displaced.

The palatine bone of the left side is in part fairly well preserved, and very similar to that in the type specimen. It has no teeth.

Part of the jugal bone is seen on the left side. It forms the whole of the lower margin of the orbit.

The lachrymal bone appears to be unusually small, and the prefrontal is also probably smaller than is usual in Anomodonts, though in the absence of the sutures it is impossible to be sure of the exact size and shape. In the upper and anterior corner of the orbit there is a low bony boss which is probably entirely formed by the prefrontal, 
The frontals are broad and probably short. The frontal region is slightly concave from side to side, and probably also somewhat concave in the antero-posterior direction.

At the outer and posterior parts of the frontal region are two very prominent ridges which pass backwards and inwards to form the sides of the parietal crest. These ridges are formed mainly by the post-orbitals, but the most anterior part of each ridge is formed either by the frontal or hy the post-frontal. Only a small part of the postorbital part of the post-orbital bone is preserved, but the greater part of the posterior process is in good condition. This posterior portion forms, as in Anomodonts generally, practically the whole of the inner border of the temporal fossi.

The parietals are no doubt long and narrow hones, but they are almost completely hidden by the post-orbitals. There is probably a large parietal foramen situated about 5 or $6 \mathrm{~cm}$. behind the plane of the post-orbital arch.

Of the occiput there are preserved the centre part showing the large condyle, and the foramen magnum, and the whole of the lower part of the left side including the ex-occipital, the lower part of the squamosal and the quadrate.

The squamosal so far as preserved resenbles pretty closely that of Dicynodon and Oudenodon. There are, however, one or two points of difference. As in the Dicynodonts generally the squamosal may be divided into three main parts: the part extending inwards to meet the parietal, the zygomatic portion which passes forwards to meet the jugal, and the descending portion which supports the quadrate. There is reason to believe that beyond the place of union of the zygomatic portion with the main part, the squamosal is continued backwards a considerable distance as a trough-like bony plate. From the centre of radiation of the bone which lies near the point of union of the zygomatic portion, the squamosal in Endothiodon appears to send inwards and downwards a well-developed process to articulate with what is probably either the supra-occipital or the ex-occipital. The state of preservation is not such as to enable one to determine the structure of this portion of the occiput. The shape of the lower part of the squamosal will be better understood by reference to the figure than by description.

The quadrate bone lies as in the Dicynodonts, below and in front of the lower part of the squamosal. Though it is impossible to describe the bone with any degree of certainty owing to the condition of the specimen, it would appear as if the bone was fairly similar in structure to that of Dicynodon and Oudenodon. The upper portion spreads out like a fan and lies against the concave descending 
portion of the squamosal. The inner part of the bone is well developed, and probably articulates with the ex-occipital. It also gives articulation to the bone which $I$ regard as the tympanic. The articular surface of the quadrate looks forwards and slightly downwards. It appears to me to be convex from above downwards and concave from within outwards.

The occipital bones are not very satisfactorily preserved, and no sutures can be detected. Though in general the occiput resembles that of Dicynodon there are one or two important differences. The condyle is strikingly different from that of any reptile hitherto described. It is of large size and passes back about $25 \mathrm{~mm}$. from the foramen magnum. Instead of being convex, as in almost all reptiles, it is concave in the centre. At the sides it is fairly flat, while the lower third is distinctly convex. Though no sutures can be made out, it is probable that the lower convex part is formed by the basi-occipital bone and that it articulates with the large lower piece of the atlas. The side parts which appear to articulate with the arch of the atlas are probably formed by the ex-occipitals.

The foramen magnum is of small size and about twice as high as broad. The supra-occipital bone, or at least that portion of the occiput above the foramen magnum, is directed almost vertically upwards.

The lateral part of the ex-occipital is well developed and is fairly similar to that of Dicynodon. Instead, however, of heing directed mainly outwards, it passes in Endothiodon almost as much backwards as outwards, so that the posterior point of the ex-occipital is as much behind the condyle as the condyle is behind the foramen magnum. There is apparently a pretty large foramen between the ex-occipital and what is possibly the supra-occipital.

The bone which lies below the ex-occipital, and which I regard as the tympanic, is considerably stouter than in Dicynodon and Oudenodon. Its relations, however, appear to be exactly similar in that it lies between the quadrate and the par-oceipital process.

The basi-occipital bone so far as preserved agrees very closely with that in Dicynodon.

There is a small part of the basi-sphenoid preserved which shows that it sent a plate-like process down in front of each par-occipital process exactly as in Dicynodon.

The mandible has lost the posterior halves of both rami, but the anterior part of the jaw is well preserved. The fused dentaries and the united splenials are present in almost perfect condition, and there are also seen portions of the angulars and part of the left sur-angular. A small portion of the left articular is attached to the 
left quadrate. In the type specimen the lower jaw as well as the snout is very badly crushed, and the extreme massiveness of the jaws is not readily appreciated. Though the mandible differs considerably from that of either Dicynodon or Oudenodon, it agrees rather more with the former than with the latter. In the tusked Dicynodon the front of the lower jaw is much compressed to allow it to pass between the long tusks, and as is the case in the sabretoothed tiger's, the anterior part of the jaw is greatly deepened. In Oudenodon the front of the jaw is much broader than in Dicynodon and relatively less deep, but otherwise the two closely resemble each other. In Endothiodon the jaw, though essentially similar in structure to that of the other Anomodonts, is different in front from that of either Dicynodon or Oudenodon in being much more powerfully built.

The two dentaries, which are anchylosed, make with one another an angle like the letter $\mathbf{V}$. There is little doubt that the jaw in front has ended in a sharp upturned point which fitted into the V-shaped depression in the front of the upper jaw. The upper border of each dentary behind the pointed portion has two parallel ridges about $12 \mathrm{~mm}$. apart, and inside of the second ridge are the teeth. There is one main row of teeth which has, especially towards the hinder part, an irregular second row of smaller teeth inside and another imperfect row of small teeth outside. The symphysis of the jaw is mainly formed by the powerful splenials, which are anchylosed together, and apparently also anchylosed to the dentaries. A little behind the symphysis each dentary is separated from the splenial by the angular passing forward between them. Immediately outside of the anterior part of the angular the dentary is very much thickened, forming a very marked tuberosity. It is highly probable that practically the whole of the outer surface dentaries has been covered by a horny sheath.

Though Seeley (6) in his account of the lower jaw says nothing of the structure, it is possible from his figure to obtain some idea of the bones forming the posterior part. In the post-dentary portion he shows that there is a deep excavation on the outer side and figures a suture crossing it from above downwards and backwards. There is little doubt that the bone above the suture is the sur-angular and the lower bone the angular. The depression is somewhat similar to the depression in the jaw of Oudenodon trigoniceps. The articular region is described by Seeley as "convex from above downwards, wider above than below, and deeper than wide; it measures $7 \mathrm{~cm}$. deep by $4 \mathrm{~cm}$. wide as preserved, but may have been heartshaped, with a concavity indenting the superior border. Its lateral 
and inferior margin is rounded." If the articular condyle is as thus described Seeley would be right in concluding that its form "indicates a difference from Dicynodontia and all other Anomodontia hitherto described." I am, however, inclined to fancy that much, if not the whole of the articular, is lost from Seeley's specimen, and that the articular region did not differ greatly from that in Oudenodon.

The atlas vertebra is as in the Theriodonts and most probably also the Dicynodonts, composed of an arch above and a welldeveloped inferior element. Owing to the difficulty of satisfactorily removing the matrix it is impossible to give a full description of this and the other vertebrx, but sufficient is displayed to reveal the principal characters. The two halves of the arch appear to be anchylosed and form a short spine. The lower portion of the arch which articulates with the occipital condyle is strongly developed. The articular surface appears to look forwards and a little inwards and to be slightly concave. The two articular surfaces are about $10 \mathrm{~mm}$. apart. From the region of the articulation there passes backwards and slightly outwards a strong transverse process or rib. There is no indication of the process being an autogenous element, and in the absence of evidence it may perhaps be safer to regard it as simply a transverse process. Whether there may have been a rib beyond the process the evidence does not show, but it seems improbable. The inferior element is somewhat similar in appearance to the intercentra of the Stegocephalians. It has in front an articular surface which appears to be concave in the vertical direction. It has also an articular surface behind for the odontoid process. Above the arch of the atlas is a well-developed pro-atlas. It is formed as in the Theriodonts and Anomodonts of two portions. Each portion has a distinct zygomatic process for articulation with the arch of the atlas.

The axis is moderately large. As in mammals and most reptiles it is composed of a normally constructed vertebra with the centrum of the atlas united with it as the odontoid process. The odontoid process, though evidently firmly united with the body proper of the axis, is probably not completely anchylosed with it, as there is a very distinct groove dividing the two elements. Only the posterior part of the odontoid process is displayed. It has a distinct articular surface for the inferior element of the atlas, and is at the posterior part only a little narrower than the body proper of the axis. The body of the axis has on either side and towards the posterior half of the body two deep furrows which approach but do not meet each other at the middle line below. The body is concave behind, On 
the level of the upper border of the body there is developed what is evidently a robust transverse process. There is no trace of a rib, but it seems probable that a small rib has been articulated to the lower side of the transverse process and the outer side of the body. The posteriol zygapophyses lie for the most part inside of the prezygapophyses of the third cervical vertebra. The axis has a fairly prominent spine, but it is not much developed antero-posteriorly.

Beyond the axis there are preserved three cervical vertebro which may be the third to the fifth, but it is perhaps more probable that they are the fourth to sixth. The three vertebræ very closely resemble each other, and they also resemble pretty closely the axis apart from the odontoid process. For convenience they will be referred to as the fourth, fifth, and sixth. The body of each vertebra has similar lateral grooves to those seen in the axis. The front half of the under side of the body is moderately flat transversely and forms on each side a small tubercle for the rib. The transverse processes are very well developed and pass directly outwards on a level with the upper border of the body. The total width of each vertebra is a little less than three times the width of the body. The spines are lost and the structure of the zygapophyses is not well shown. The structure of the proximal ends of the ribs of the three vertebris is fairly well seen. Eisch rib is double-headed and the two heads are rather widely apart, the one articulating with the lower outer and anterior corner of the centrum, and the other with the under side of the outer part of the transverse process. The portion of the rib hetween the two articulations makes with the shaft an appearance like the letter $Y$. The shaft is slender.

The next series of vertebræ are probably. the seventh to the eighteenth. The tirst of the series resembles pretty closely the sixth cervical and is probably the seventh cervical. The rest of the vertebrie are probably all dorsals. The seventh cervical is slightly imperfect. It differs from the more anterior cervicals in having the libs more robust. The shaft of the rib passes backwards, outwards, and downwards; and though the rib is still two-headed, the surface for articulation with the underside of the transverse process is so long that it almost joins the articulation for the centrum.

The vertebra which follows the supposed seventh cervical and which is probably the first dorsal shows the centrum to be slightly different from that of the more anterior vertebr'œ. The articulation for the head of the rib forms a less marked tubercle owing apparently to the head of the rib articulating in part with the interarticular fibro-cartilage. In the second dorsal the tubercle is less developed than in the first, while in the third dorsal the 
268 Transactions of the South Arrican Philosophical Society.

tubercle has almost disappeared and no trace of it can be seen in the fourth. As the articular surface disappear's from the front of the side of the body, an articulation begins to appear on the posterior part of the side. The third dorsal has as large an articulation on the posterior part of the side of the body as on the anterior. Each of the first three dorsals has well-developed transverse processes. In the third they are shorter than in the other two, and in the more posterior vertebræ they become much shorter. The ribs have large articulations with the undersides of the transverse processes, and it is probable that this articulation is continuous with the articular surface of the body and that the ribs are singleheaded. The zygapophyses are situated above the level of the transverse processes and are fairly closely together. The spines of the anterior dorsals are short.

The posterior dorsal vertebra differ from the anterior in having the bodies narrower, deeper, and longer. The width across the transverse processes in the case of the ninth vertebra is less than twice the width of the body. There is little doubt that all the ribs of the posterior dorsal vertebræ are single-headed. The zygapophyses are even closer together than in the anterior dorsals. On passing backwards the ribs articulate less and less with the bodies, and in the posterior dorsal region the articulations seem to be almost entirely with the transverse processes.

The sacrum is well preserved and fairly well displayed. It appears to have consisted of only four vertebræ, and if a fifth was united to the fourth it is unlikely that it gave any support to the ilium. In general appearance the sacrum is not unlike that of the human subject. The body of the first vertebra is broader than deep, and is somewhat excavated at the sides. The sacral rib is of large size. It articulates with the upper part of the body and with a large part of the side of the arch. On passing outwards it expands backwards, forwards, and upwards, and supports the anterior part of the ilium. Each rib is about as wide as the body of the vertebra. The second sacral vertebra has the body considerably longer than the first. like the first it has the two sides slightly excavated. The rib is shorter than that of the first, but it expands to a much greater extent upwards, so that the height of the outer expanded portion is almost as great as that of the whole vertebra. It exteuds from the lower border of the ilium to within a short distance of its upper border. The third and fourth sacral vertebre are very similar to the second, only somewhat smaller, but the ribs, though they extend about as far upwards, do not expand so far downwards as in the second vertebra. Almost the whole of the expanded apper part of 
the ilium is supported by the four sacral vertebre. There are no caudal vertebra preserved.

The shoulder girdle is very imperfectly preserved, the only parts remaining being the lower part of the right scapula with part of the precoracoid, and a portion of the top of one of the scapula, probably also the right. So far as preserved the scapula agrees pretty closely with that of Dicynodon and Oudenodon. There is a well-developed expansion in front which articulates with the precoracoid, and there is evidence of there having been a distinct acromion, but whether this was as well developed as in Dicynodon the evidence does not satisfactorily show. On the inner side there is at the lower end, as in the Dicynodont scapula, a deep groove leading down to the precoracoid foramen. The glenoid surface of the scapula is nearly at right angles to the axis of the bone. The precoracoid is well developed but appears to have been relatively smaller than in Oudenodon. The precoracoid foramen on the outer surface opens about $10 \mathrm{~mm}$. below the suture with the scapula. In this it differs from the Dicynodont condition and agrees with the condition in the Therocephalians (c.g., Ictidosuchus). It is interesting to note that the anterior border of the precoracoid does not extend so far in the direction of the precoraco-scapular suture as does the scapula. A similar condition was long ago observed in the small Dicynodont shoulder girdle figured by Owen in his Catalogue.

The humerus, which is represented by the upper half of the right bone, is strikingly Dicynodont. The head of the bone has the same kind of broad articulation as is found in the Monotremes, Dicynodon, and Oudenodon. When viewed from above the proximal end of the bone has a somewhat sigmoid curve owing to the deltoid ridge passing forward and outward and the inner angle of the bone being directed somewhat backwards from the transverse head. The deltoid ridge is of large size and bears similar relations to the head as does the ridge in Dicynodon and Oudenodon. At its lower angle the ridge does not form in downward process as in some species of Oudenodon (c.g., Oudenodon maynus $[=$ Platypodosaurus robustus $]$ ). On the posterior surface of the humerus a well-developed ridge passes down the bone from the articular surface. On the inner edge of the bone, near the level of the lower margin of the deltoid ridge, is a fairly welldeveloped tricipital ridge. It is thus somewhat lower in position than the corresponding ridge in "Platypodosaurus," and it is less prominent. This ridge has been supposed to be absent in Dicynodon, but though less developed than in Oudenodon, it is quite distinct in at least some species of Dicynodon. Close to the lower border of the tricipital ridge is situated the beginning of the entepicondylar foramen. 
The pelvis, which is represented by both ilia and portions of both pubes and ischia, is so far as preserved very like the pelvis of Oudenodon. Both ilia are broken across at the constricted portion, but fortunately practically nothing is lost at the seat of fracture on the left side, and the parts can be fitted together. On the right side the fractured surfaces have been much weathered and the bones badly crushed, so that there is a little doubt as to whether the parts have been correctly joined. The ilium is a large bone which terminates above in a long semi-circular crest. The upper portion is fairly flat, but the first half is somewhat concave owing to the anterior part of the ilium being directed outwards. Almost the whole of the upper portion of the ilium is supported by the four large sacral ribs. Posteriorly the upper portion of the ilium ends in a rather sharp process. The middle portion of the ilium is much constricted, and on the posterior side there is a very deep notch between the upper flat portion and the lower articular portion. The acetabulum is of large size and closed as in mammals. The lower portion of the ilium forms nearly half of it, and the articular surface of the ilium looks downwards, outwards, and backwards. The pubis is only represented by the upper or acetabular portion, but though broken off a short distance below the acetabulum, enough remains to show that there was a distinct though probably not very large ischiopubic or obturator formen. There is also evidence of there having been in front a distinct pectineal process. The ischium, like the pubis, is broken off a little distance below the acetabulum. It is a much larger bone than the pubis.

The upper and lower portions of both femora are preserved, but unfortunately all the portions are considerably crushed, and it is thus impossible to give a satisfactory description of the bones. On the whole the feinur agrees pretty closely with that of Oudenodon.

The upper ends of both tibix and of one fibula are preserved. As in Oudenodon, Lystrosuurus, and "Dicranozygoma," the head of the fibula is larger than the head of the tibia. In Endothiodon, as in Lystrosaurus, it is very much longer. The head of the fibula articulates with the side of the head of the tibia and also gives a fairly large articulation to the femur. The heads of both tibix are crushed and imperfectly displayed. They are about as broad as deep. There is a deep groove for the tibialis anticus muscle, as in Pareiasaurus.

The following are some of the principal measurements :-

Snout to back of post-orbital arch $180 \mathrm{~mm}$.

Width of frontal region 
Width of parietal crest $29 \mathrm{~mm}$.

Width of back of skull 324

Width of mandible at back of dentaries.......... 117

Greatest width of humerus ........................ 98

Length of four sacral centra $\ldots \ldots \ldots \ldots \ldots \ldots \ldots . . . \ldots 5$

Length of iliac crest .......................... 125

Length of ilium ............................ 154

\section{ESOTERODON UNISERIES (Owen).}

This Endothiodont reptile was described by Owen in 1879 (5) from a snout sent to the British Museum by Mr. T. Bain. Though Owen in his paper does not give any locality for the specimen, in the British Museum Catalogue (1890) Lydekker (4) states that the specimen came "from the Beaufort beds on the flanks of the Nieuwveldt range." The specimen consists of the anterior part of a skull which bears some resemblance to that of Endothiodon bathystoma, but differs, among other things, in only having a single row of teeth. Owen described it under the name Endothiodon uniseries, and, comparing it with Oudenodon and Dicynodon, concluded that " the cranial characters are Anomodont." The row of teeth Owen appears to have regarded as belonging to the palatine bone, and the real palatine bone he looked upon as the pterygoid. Lydekker pointed out Owen's error, and gave what is no doubt the correct interpretation of the bones.

Seeley in 1895 (2) regarded the fossil as the type of a new genus, and though there is no doubt that it is closely allied to Endothiodon, I agree with Seeley in placing it in a distinct genus.

In $1900 \mathrm{I}$ published a restoration of the palate, and showed the structure and relations of the vomer.

With the exception of the type specimen no other remains have hitherto been known. In the collection of fossils obtained by $\mathrm{Mr}$. T. Bain, and recently presented to the South African Museum by his son, Mr. J. M. Bain, there are two specimens which almost certainly belong to this form. The first of these is the anterior portion of the left mandible. It not only belongs to this species, but it is in the highest degree probable that it is the mandible of the same individual. Most likely Mr. T. Bain found the jaw at the same time as the snout, and when sending the snout to the British Museum apparently omitted to send the jaw-possibly thinking the snout was all that was required to determine the form. The second specimen is the crushed occiput and posterior part of the base of the skull. This is also almost certainly a part of the skull of Esotcrodon 


\section{Transactions of the South African Philosophical Society.}

uniseries, and most likely also belonging to the same individual as the type.

The specimen which represents the back portion of the skull, on the whole, bears a fairly close resemblance to the corresponding portion of the skull of Dicynodon.

The occiput is fairly well preserved, though somewhat crushed. The occipital condyle is like that of Endothiodon bathystoma, excavated in the centre. When viewed from behind it is kidney-shaped, and about twice as broad as deep. The under side is flattened by the articular surface passing in below the condyle for a considerable distance. The posterior surface is, except for the deep central excavation, moderately flat. The upper and outer corners are rounded, and the middle portion of the upper side passes backwards as a distinct though small ridge. At the outer side of the base of the condyle is a large foramen as in Dicynodon. Immediately above the foramen is a little rough transverse tubercle for the attachment of some muscle. The foramen magnum is a little higher than broad, and is narrower above than below. At either side of the foramen there is a well-developed rounded tubercle, similarly situated to that in the occiput of Ptychosiagum oricntale. The sutures cannot be made out, and the limits of the ex-occipital are therefore uncertain. The portion of occiput above the foramen magnum slopes forward. In the specimen much of the slope is due to crushing, but it is probable that even in the uncrushed condition the slope is considerable. The ex-occipital has a well-developed external process for the support of the squamosal, as in Anomodonts generally. The downward processes of the basi-occipital are flatter than in the Dicynodonts, but this may be due in part to crushing. In front they are overlapped by the basisphenoid, as in Dicynodon and Oudenodon. In the middle of the basisphenoid there is a deep pit, but whether it ends blindly or leads into a foramen is not revealed in the specimen. On either side of this median pit is a foramen which is probably the carotic foramen. Outside of this and a little in front is a larger foramen. This region of the Anomodont skull is the only region of which the anatomy is still unknown, and as I expect shortly to be in a position to give a detailed account of the sphenoid region, it will perhaps be better to avoid speculation on one or two points, which may possibly be cleared up by one or two specimens which are being sectioned. The back part of the pterygoids is fairly well preserved. It is chiefly noteworthy from the formation by the united pterygoids behind the oval median pterygoid pit of a prominent but very blunt keel.

The lower jaw is represented by the greater part of the left dentary 
and splenial, and a small part of the angular and sur-angular. There is a marked general resemblance between this jaw and that of Endothiodon bathystoma, but the present jaw is of much lighter build. The dentary has no doubt been anchylosed to that of the other side, and the jaw has ended in front in a sharp upwardly directed process. The upper border of the dentary as preserved shows that portion which met the maxillary. Externally it has a sharp ridge which was probably covered by horn in the living animal. Within this ridge is a groove followed by another ridge. The two ridges are $10 \mathrm{~mm}$. apart. To the inner side of the inner ridge lies the row of teeth. In the specimen the roots of only five are preserved, but there appear to have been at least ten and possibly eleven teeth in the row originally. The last, however, is rudimentary, and the second last small. Owen considers there are nine in the upper jaw. The lower part of the symphysis, and possibly more than half, is formed by the well-developed splenial. The splenial also forms about two-thirds of the inner surface of the portion of the jaw between the symphysis and the lateral fenestra. The anterior portion of the angular fits in between the splenial and the dentary as in Endothiodon bathystoma. The anterior part of the sur-angular articulates with the dentary above the lateral fenestra.

The following are the principal measurements :-

$\begin{array}{llr}\text { Depth of jaw in posterior molar region } \ldots \ldots \ldots \ldots . & 60 \mathrm{~mm} . \\ \text { Length of molar series (as preserved) } & \ldots \ldots \ldots \ldots . & 67 \\ \text { Width of occipital condyle } \ldots \ldots \ldots \ldots \ldots \ldots \ldots \ldots \ldots & 37 \\ \text { Depth of occipital condyle (in middle) } & \ldots \ldots \ldots \ldots . & 17 \\ \text { Width between ex-occipitals } \ldots \ldots \ldots \ldots \ldots \ldots \ldots \ldots & 128\end{array}$

\section{Cryptocynodon simus, Seeley.}

This genus, which is closely allied to Esoterodon, is only known by the type specimen which was discovered by Seeley at Molteno Pass, in the Nieuwveldt range. Unfortunately the type specimen consists of only the preorbital portion of the skull, and that in a bad state of preservation. It shows the presence of a single row of simple molars as in Esoterodon, with the addition of a small canine in front of and to the outer side of the row of molars. The arrangement of the palate is very similar to that in Esoterodon, the vomer uniting with the posterior median process of the premaxilla as in that genus, and the suggestion might be made that possibly this is a very young specimen of Esoterodon uniseries, the small canine being 
lost in later life. Owing to the very imperfect condition of the type specimen it is impossible to settle the point beyond doubt. In the meantime it will perhaps be safest to regard it as a distinct form.

A restoration of the palate is given in fig. 19, pl. xiii.

\section{Prodicynodon pearstonensis, Broom.}

This interesting type, which is unfortunately known only by the front half of the skull, and that in a rather imperfect condition, was recently described by me (9) in Records of the Albany Museum. It was found at Pearston, Cape Colony, in the Lower Karroo beds. In general appearance the skull resembles considerably that of Dicynodon, but it differs, among other things, in having a few molar teeth arranged in two rows.

The premaxillary portion of the beak is much broader than is usual in Dicynodon, and also flatter. On the upper surface of the snout only the impressions of the bones remain, and it is a little difficult to be certain about the sutures. The premaxillary certainly passes backwards on the upper side of the snout a short distance, but how far cannot be decided with absolute certainty. In the figure I previously gave of the upper side of the specimen I figured the premaxillaries as passing back between the nasals as far as the front of the frontals. I am now inclined to think that the posterior half of the portion of the snout in front of the frontals is really made up of the nasal bones, and that what I believed to be a suture between the nasal and premaxilla is the impression of a groove on the under surface of the nasal produced by a blood-vessel or nerve. If this latter be the correct view the nasal, instead of being a small element, would be a fair-sized bone. The inter-orbital portion of the skull is much narrower than is usual in Anomodonts. The pterygoids and palatines, so far as preserved, are very similar to those bones in Dicynodon and Oudenodon. The lower jaw is not unlike that of some of the smaller species of Oudenodon, especially $O$. trigoniceps. The dentary has a well-marked longitudinal ridge above the fenestra. The angular fits in between the dentary and the splenial in the same way as in Endothiodon. The canine tooth is round and is relatively smaller than in most Dicynodons, and it is directed well forwards, as in those specimens which are believed to be females. The molar teeth are few in number, arranged in two or possibly three rows, and are not serrated.

In fig. 22, pl. xiii., is shown a restoration of the side view, and in fig. 21 , pl. xiii., a restoration of the palate. 


\section{Opisthoctenodon agiLis, Broom.}

This small Endothiodont which, like the previous one, was found at Pearston, and in the same stratum, is represented by a fairly well preserved skull, clavicle, interclavicle, sternum, humerus, radius, and ulna of both sides, carpus and some phalanges of the right manus and portions of the left.

The skull is very like that of a small Oudenodon, and, apart from the presence of molar teeth, I am not aware of any cranial character that would distinguish the two genera. The skull has been already figured in upper view (9). If this figure be compared with the figures of Kistecephalus arctatus given by Owen, it will be seen that the resemblance is sufficiently close to make it possible that Owen's species may belong to Opisthoctenodon. Lydekker (4) expresses doubt as to its being a Kistecephalus. One of the specimens (47088) at least most probably belongs to this genus.

The teeth are confined to the maxillary and dentary bones. There appear to be five mature teeth, and there are very clear evidences of replacing teeth developing to the inner sides of the mature ones. Those teeth which are well preserved are seen to have a smooth anterior edge and a deeply serrated posterior border, there being seven denticulations on the only perfect tooth.

The lower jaw is unusually flat and broad in front.

The clavicle is long and slender and very mammal-like. It is curved almost exactly as in man.

The interclavicle is a small, flat, shield-like plate, of which the anterior border is moderately straight and the posterior border rounded.

The sternum is an irregular, rounded flat plate, which is considerably broader in front than behind. It differs greatly in appearance from the interclavicle in that while the latter is formed of dense bone, the sternum has been either cartilage or ossified cartilage or very spongy bone.

The humerus is typically Dicynodont. The large deltoid ridge extends over more than half of the bone. At its lower margin is situated the entepicondylar foramen.

The radius and ulna are not very well preserved, but both bones are fairly similar to those of Oudenodon. The ulna has the olecranon process considerably less developed than in Oudenodon trigoniceps.

The carpus I have already described elsewhere. It consists as in Oudenodon, Theriodesmus, and most primitive reptiles, of four elements in the proximal row, viz., radiale, intermedium, ulnare, and pisiform, of two centralia, and of a distal row of carpalia. In 
Oudenodon there are apparently five carpalia, in Opisthoctenodon there is evidence of only four. To the radial side of the first digit there is evidently a prepollex. It consists of a distal element lying by the side of the first metacarpal, and with a broad distal end. A small element which appears to support the metacarpal-like element articulates with the radiale and first carpale apparently. A third element lies to the radial side of the more proximal of the prepollex elements. This third element, however, may have nothing to do with the carpus. In the specimen the carpus is crushed into the base of the skull, and owing to the small size of the specimen, and the impossibility of doing much in the way of development, it is difficult to determine whether this third bone belongs to the carpus or is part of the crushed skull. I have figured it as it occurs.

The metacarpals and phalanges are well developed and much more slender than in Oudenodon. The fifth digit is not preserved. There is a small portion of the fifth metacarpal, but whether the portion is the remains of a well-formed digit or the whole of an imperfect one the evidence does not show.

\section{OPISTHOCTENODON BRACHYOPS, n. sp.}

This new species is founded on a small skull which has for very many years been in the collection of the South African Museum. It is believed to have come from the Beaufort West District, but the exact locality is uncertain.

Though the specimen is badly weathered it is possible to make out most of the characters. The orbits are fairly round, and look more outwards than upwards. The post-orbital arches, though slender, are more robust than in $O$. agilis. The parietal region is considerably broader than the frontal, and is moderately flat. There is a large pineal foramen and a distinct pre-parietal bone. The post-orbital bone forms almost the whole of the inner wall of the temporal fossa. Posteriorly it meets the squamosal. The posterior zygomatic portion of the squamosal is flat and directed outwards. The anterior part of the squamosal extends forward to under the orbit, but does not meet the maxilla. The jugal is well developed. The maxilla is a strongly developed bone. In front of the lower corner of the orbit is a distinct depression in the bone. The caniniform process is situated almost immediately in front of the plane of the orbit, and is very strong.

The mandible is not well preserved, but in general structure it agrees with Oudenodon. There are apparently four developed teeth with replacing teeth developing on the inner side. There is a distinct socket for at least some of the teeth. 


\section{Pristerodon mackayi, Huxley.}

Pristerodon is closely allied to Opisthoctenodon, but differs in having two well-developed tusks. The only known specimens have been found at East London in beds of probably similar age to those of Pearston and Beaufort West. In Huxley's type, which is now in the British Museum, there is no evidence of tusks, but this is probably due to the imperfection of the specimen. In a specimen sent many years ago to the South African Museum by Mr. G. McKay the tusks are very distinct. In other respects the South African Museum specimen agrees closely with Huxley's type. The whole skull is more strongly built than in Opisthoctenodon. In the middle line of the snout is a prominent median ridge, and there is a parallel ridge above each nostril as in Esoterodon. The mandible is broader and shorter than in Opisthoctenodon, and turns up much more abruptly in front. At the back part of the dentary is a very strong longitudinal ridge, which passes directly outwards. There are considerably more teeth in the jaw of Pristerodon than in Opisthoctenodon. In the South African Museum specimen there are at least six in a row.

\section{Chelyoposaurus williamsi, Broom.}

The type of this species was discovered in a block of sandstone in the Premier Diamond Mine at Kimberley by Mr. Gardner Williams, after whom the specimen has been named. A preliminary description was published in the Records of the Albany Museum (9).

The specimen is represented by most of the presacral vertebra, many ribs, the right arm, the left femur, and a small portion of the skull. Probably only the atlas is missing among the presacral vertebræ, and if this be so then the full number would be twenty-six. The vertebræ being split through are not very well preserved, but their relative sizes and some other points are seen in the figure given. The ribs are slender and, so far as can be seen, all single headed. The arm is not well preserved, and does not show any features not better seen in other Anomodonts.

The thigh bone is very like that of Oudenodon, having a broad upper end and a narrow middle portion.

The skull fragment consists of most of the left squamosal and jugal bones, a considerable portion of the maxilla, and most of the back part of the mandible. The bones are very like those of Oudenodon, but the specimen is removed from that genus by the presence of a small maxillary tooth. The evidence does not show if there have been more, but it is probable. The tooth is moderately flat, 
and has no serrations. It would thus seem that Chelyoposaurus bears a similar relation to Prodicynodon that Opisthoctenodon does to Pristerodon.

\section{AfFinities OF The Endothiodonts.}

It will be observed that while the various Endothiodonts have many characters in common, they can be divided into two groups, the members of which are much more closely related to each other than to the members of the other group. Thus it is manifest that Esoterodon is closely related to Endothiodon and Cryptocynodon, and that Pristerodon is a near ally of Opisthoctenodon. Prodicynodon, though less specialised than the other genera, comes nearer to Pristerodon than to Cryptocynodon.

We may imagine the common ancestor of the Endothiodonts to have been a form somewhat intermediate between Cryptocynodon and Prodicynodon, with well-developed canines and with a single row of molars serrated in front and behind. By one line of descent there arose Endothiodon, the intermediate stages being Crytocynodon and Esoterodon. A second line gave rise to Pristerodon and Opisthoctenodon, where the molars are only serrate behind. In the third line the molars became degenerate as in Prodicynodon, and finally lost as in Dicynodon and Oudenodon. Though there is great probability that Dicynodon is descended from Prodicynodon, or a closely allied form, there is considerable doubt as to whether Oudenodon is descended from Dicynodon by the loss of the tusk. The tuskless Endothiodonts, such as Opisthoctenodon, resemble Oudenodon much more closely in general characters than does Dicynodon, but it may be that the loss of the tusk in Opisthoctenodon and Oudenodon has brought about a similar development in the two genera. In the meantime we may regard Oudenodon as bearing the same relations to Dicynodon that Opisthoctenodon does to Pristerodon.

The discovery of the small Endothiodonts has pretty well bridged over the gap between Endothiodon and Oudenodon, and the question might well arise, are we justified in putting Endothiodon in a different family from Oudenodon? Had Dicynodon been a terminal type it would have been convenient to have put it in the same family as the Endothiodonts, but no sooner would it appear were the molars lost than a large number of molar-less forms arose-Lystrosaurus, Kistecephalus, Gordonia, Geikia, and probably one or two others. It therefore seems advisable to place those forms which apparently have sprung from Dicynodon or a closely allied form in one family- 
the Dicynodontidæ, and the other Anomodonts, which have molars, in a separate family-the Endothiodontidæ.

With regard to the origin of the Endothiodonts little is known. There is no doubt that there is some affinity between the Anomodonts and the Theriodonts, and though neither can be descended from the other, both doubtless had a common ancestor. There is strong probability that this common ancestor was one of the Therocephalians, but at present unknown. The cranial characters are strikingly similar in the Anomodonts and Therocephalians, and the other skeletal characters also point to a close relationship. When a Therocephalian is discovered which shows a degeneration of the incisor teeth we shall probably have a form allied to the ancestor of the Anomodonts.

The known Endothiodonts may be arranged phylogenetically thus :-

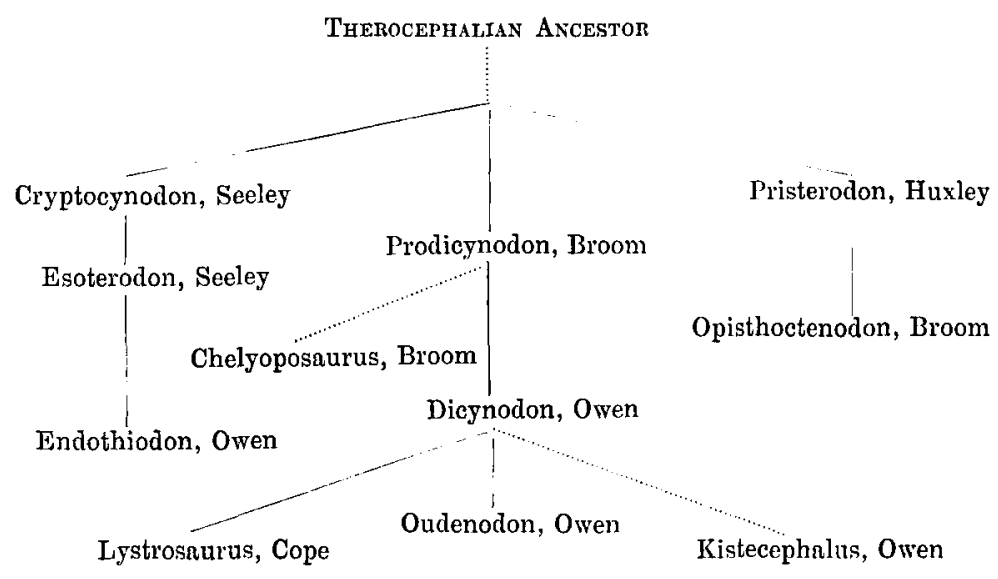


$(280)$

\section{REFERENCES TO LITERATURE.}

(1) T. H. Huxley. "On Saurosternon bainii and Pristerodon mackayi," Geol. Mag., vol. v., 1868.

(2) H. G. Seeney. "Researches on the Structure, \&c., of the Fossil Reptilia," ix. 1. "On the Therosuchia," Trans. Roy. Soc., vol. clxxxv. B., 1894.

(3) R. Ownn. "Descriptive and Illustrated Catalogue of the Fossil Reptilia of South Africa in the Collection of the British Museum," London, 1876.

(4) R. Lydekker. "Catalogue of the Fossil Reptilia and Amphibia in the British Museum," pt. iv., 1890.

(5) R. Owen. "On the Endothiodont Reptilia with Evidence of the Species Endothiodon uniseries, Ow.," Q.J.G.S., vol. $x x x v ., 1879$.

(6) H. G. Seeley. "On Further Evidence of Endothiodon bathystoma, Owen, from Oude Kloof," Q.J.G.S., vol. xlviii., 1892.

(7) R. Broom. "On the Structure of Palate in Dicynodon and its Allies," Tr. S. Af. Phil. Soc., vol. xi., part 3, 1900.

(8) R. Broom. "On some Points in the Anat. of Anomodont Skull," Rec. Alb. Mus., part 2, 1904.

(9) R. Broom. "On two new Endothiodont Genera (Opisthoctenodon and Prodicynodon)," Rec. Alb. Mus., part 2, 1904.

(10) R. Broom. "Notice of a new Endothiodont Genus (Chelyoposaurus)," Rec. Alb. Mus., part 3, 1904.

(11) R. Broom. "On the Origin of Mammalian Carpus and Tarsus," Tr. S. Af. Phil. Soc. vol. xv., part 4, 1905. 
(281)

\section{REFERENCES TO FIGURES.}

Ac. Acromioñ ; Ang. Angular ; B.O. Basi-occipital; B.S. Bnsisphenoid; $c^{r}$ and $c^{2}$, centralia 1 and 2 ; Civ-Cvii, Cervical vertebræ iv and vii; C.Ax. Centrum of Axis ; Cl. Clavicle; Co. Coracoid; D. Dentary; Di, Dx, Dxi, Dorsal vertebre 1, 10, and 11 ; Ent. For. Entepicondylar foramen; E.O. Ex-occipital ; F.M. Foramen Magnum ; G.C. Glenoid cavity ; i. Intermedium; I. Cl. Interclavicle ; Il. Ilium ; Is. Ischium; L. At. Lower piece of Atlas; Mx. Maxilla; O.P. Odontoid process; Pa. Parietal ; P. At. Pro-atlas ; P. Co. Precoracoid ; P.F. Pineal foramen; pi. pisiform; Pmx. Premaxilla; P.O. Post-orbital: P. Pa. Preparietal; Pt. Pterygoid; Pu. Pubis; Qu. Quadrate; R. Radius; r. radiale : S.A. Sur-angular; Sc. Scapula; Sp. Splenial ; Sp. Ax. Spine of Axis ; Sq. Squamosal ; St. Sternum ; T. At. Transverse process of Atlas; T. Ax. Transverse process of Axis; Ty. Tympanic; U. Ulna; u. ulnare; Vo. Vomer; $x$. and $y$. bones of prepollex; $z$. doubtful element probably not belonging to carpus.

\section{Plate XII.}

Fia.

1. Side view of skull of Endothiodon bathystoma, $\times \cdot 37$.

2. Upper " " " " $\times 37$.

3. Under view of mandible of Endothiodon bathystoma, $\times \cdot 37$.

4. Occiput of Endothiodon bathystoma, $\times-37$.

5. Upper view of vertebra of Endothiodon bathystoma, $\times \cdot 22$.

6. Under " ", ", $\quad$ " 22 .

7. Front view of atlas and pro-atlas of Endothiodon bathystoma, $\times \cdot 22$.

8. Side view of right shoulder girdle of , $\quad, \quad \times 22$.

9. Inner " " , " , " , $\quad \times \cdot 22$.

10. Front view of right humerus of $", \quad ", \quad \times \cdot 22$.

11. Side view of pelvis of Endathiodon bathystoma, $\times \cdot 22$.

12. Upper " " and sacrum of Eulothiodon bathystoma, $\times \cdot 22$.

13. Under ," , ", ", ",$\quad \times \cdot 22$.

14. Front view of right femur of " $", \quad ", \quad \times \cdot 22$.

Plate XIII.

15. Side view of skull of Esoterodon uniseries, $\times \cdot 42$.

16. Underside , " , ", (pal. after Owen) $\times \cdot 33$.

17. Occiput of Esoterodon uniseries, $\times \cdot 54$

18. Portion of mandible of Esoterodon uniseries, $\times \cdot 23$. 
282 Transactions of the South African Philosophical Society.

Fia.

19. Restoration of palate of Cryptocynodon, $x \cdot 6$.

20. " " Endothiodon, $x \cdot 23$.

21. ", ", Prodicynodon. Nat. size.

22. " skull of Prodicynodon pearstonensis, Nat. size.

23. Skull of Opisthoctenorlon brachyops, from above, $\times \cdot 82$.

24. " " " $"$ side view, $\times \cdot 82$.

25. " " " $"$ agili: (restored slightly). Nat. size.

26. Clavicle, inter clnvicie, and sternum of Opisthoctenodon agilix, $\times 1 \cdot 13$.

27. Left humerus of Opisthoctenodon agili, $\times 1 \cdot 13$.

28. Left forearm and manus of Opisthoctenodon agilis, $\times 1.13$.

29. Right manus of Opisthoctenodon agil: $\times, \times 1 \%$.

30. Molar tooth of,$\quad \times 5$

31. Skeleton of Chelyoposaurus williansi, $\times 54$.

32. Hestoration of skull of Pristerolon mackayi. Nat. size.

Plate XIV.

33. Restoration of skeleton of Fndothiodon lathystoma. Reduced. 